\title{
WHEAT STRIPE RUST CONTROL USING FUNGICIDES IN NEW ZEALAND
}

\author{
S.L.H. VILJANEN-ROLLINSON, M.V. MARRONI and R.C. BUTLER
}

\author{
Crop \& Food Research, Private Bag 4704, Christchurch, New Zealand
}

Corresponding author: viljanens@crop.cri.nz

\begin{abstract}
A field trial in 2005 used eight fungicide treatments and two wheat cultivars, Karamu and Kohika, differing in susceptibility to wheat stripe rust. Fungicides were applied at different growth stages of the crop and different levels of stripe rust. Disease severity assessments, percent leaf area infected for individual plants and leaves, were made at regular intervals and area under the disease progress curve (AUDPC) was calculated. Mean AUDPC was lowest in the Full, Protectant and Late window treatments for all leaves on both cultivars and greatest in the Nil plots for both cultivars. Mean AUDPC generally increased with leaf age for Kohika, so that flag (F) leaves had the lowest and F-3 the greatest mean AUDPC. The same trend occurred on Karamu leaves, but was not statistically significant. Two well-timed fungicide applications achieved as good control of stripe rust in both Karamu and Kohika as the full fungicide treatment.
\end{abstract}

Keywords: wheat, Puccinia striiformis, epoxiconazole, azoxystrobin, area-under-the-disease-progress-curve, AUDPC.

\section{INTRODUCTION}

Wheat stripe rust, caused by Puccinia striiformis f.sp. tritici, is a serious disease of wheat in New Zealand. The disease is controlled by applying fungicides or planting resistant cultivars. The resistance in many wheat cultivars in New Zealand has been eroded due to virulence developing in several of the resistance genes contained in these cultivars. The pathogen is highly adaptable and more than 30 different pathotypes have been recorded in New Zealand (M.G. Cromey, pers. comm.). Fungicides from several different groups, including triazoles and strobilurins, are registered in New Zealand for the control of this disease. Fungicides can be applied either preventatively, to protect leaves from pathogen propagules that may establish infections, or as eradicants, to prevent the expression of symptoms from latent infections (Vyas 1984). The efficacy of fungicides depends partly on the crop growth stage and disease severity at the time of application. Cultivar resistance also has an impact on disease development.

This research has determined the effects of applying fungicides at different stages of crop development and stripe rust severity in two cultivars differing in susceptibility.

\section{MATERIALS AND METHODS}

An autumn-sown field trial using two wheat cultivars, Karamu and Kohika, with different susceptibilities to stripe rust, was established at Lincoln, Canterbury, New Zealand, during the 2005-2006 growing season. A mixture of two fungicides (Opus ${ }^{\circledR}$ : epoxiconazole $125 \mathrm{~g}$ ai/ha and Amistar ${ }^{\mathrm{B}}$ : azoxystrobin $250 \mathrm{~g}$ ai/ha) and eight different timings was used to control stripe rust (Table 1). Three replicates of the 16 treatment combinations (two cultivars and seven treatments, double replicates of Nil treatment), were laid out in an array of six by nine plots in a latinised resolvable block design. Each set of three rows of plots and six columns formed a replicate, and each set of nine rows of plots and two columns also contained a complete replicate. 
The trial was inoculated with pathotype 234E139A-, $Y r 17+$, which is virulent on host genes $\mathrm{Yr}$ 2, $\mathrm{Yr} 3, \mathrm{Yr}$ 4, $\mathrm{Yr}$ 7, $\mathrm{Yyr} 9$ and $\mathrm{Yr} 17$, on 9 September 2005 by planting infected plants in the trial site as described previously (Viljanen-Rollinson et al. 2002). The first disease assessment was made on 23 September. Twelve further assessments were made as shown in Figure 1. At each date, 10 plants per plot were randomly selected, and each leaf scored for the percentage leaf area infected with stripe rust and presence or absence of sporulating pustules. At the initial assessment (23 September), the flag leaf (F) and leaves F-1, F-2, F-3, F-4 and F-5 had not emerged, but all had emerged by the third assessment (8 November). The final assessment was made on 23 December, by which time all leaves on the Nil plants were dead. The raw data were not analysed formally. Data for the first and second assessments were discarded because so few leaves had emerged by the assessment date. Maximum disease severity per plot was analysed with analysis of variance.

Prior to the calculation of area under the disease progress curve (AUDPC), dead leaves were given a score equal to the mean score for that plot and leaf number at the previous date. Once all the leaves of a given number in a plot were dead, scores for that leaf were omitted from subsequent dates from the calculation of AUDPC. After these substitutions, the mean scores per cultivar, leaf, plot and date were calculated, and were used to calculate AUDPC using the formula:

$$
\text { AUDPC }=\sum_{d=0}^{n} \frac{1}{2}\left(y_{i+1}+y_{i}\right)\left(x_{i+1}-x_{i}\right)
$$

where $Y_{I}=$ stripe rust severity at the $i$ th observation, $X_{I}=$ time (d) at the $i$ th observation and $n=$ total number of observations (11). Values of AUDPC were analysed with analysis of variance, with the Greenhouse-Geisser adjustment ("repeated measures anova") as implemented in GenStat, since the leaves were measured on the same plots.

TABLE 1: Fungicide treatment descriptions and application dates.

\begin{tabular}{|c|c|c|}
\hline Treatment & Description & Date applied (2005) \\
\hline & \multicolumn{2}{|l|}{ no fungicide (double replicates) } \\
\hline ull & $\begin{array}{l}\text { 4-5 week fungicide application } \\
\text { programme }\end{array}$ & $16 / 09,20 / 10,17 / 11,15 / 12$ \\
\hline Protectant & $\begin{array}{l}\text { Fungicide application early in the growing } \\
\text { season when little rust present }\end{array}$ & $16 / 09,20 / 10$ \\
\hline Eradicant & $\begin{array}{l}\text { Fungicide application late season } \\
\text { when rust was well established }\end{array}$ & $8 / 12$ \\
\hline Early eradicant & $\begin{array}{l}\text { Fungicide application mid and late season } \\
\text { when rust epidemic was starting }\end{array}$ & $10 / 11,8 / 12$ \\
\hline Early window & Unsprayed window early in the season & $20 / 10,17 / 11,22 / 12$ \\
\hline dow & Unst & $16 / 09,17 / 11,22 / 12$ \\
\hline Late window & Unsprayed window late in the season & $16 / 09,20 / 10,22 / 12$ \\
\hline \multicolumn{3}{|c|}{$\begin{array}{l}\text { The mean disease severities on flag leaf, F-1 and F- } 2 \text { for each cultivar and treatment } \\
\text { at each date are in Figure } 1 \text {. Overall, Kohika had more stripe rust on these leaves than } \\
\text { Karamu. Disease severity was highest in the Nil and Eradicant plots for both cultivars. } \\
\text { In contrast, disease severities in the Full, Protectant, Mid window and Late window } \\
\text { treatments were below } 20 \% \text { throughout the growing season. No significant differences } \\
\text { (P }>0.05 \text { ) were found between the cultivars, leaves or treatments for mean maximum } \\
\text { disease severity. The mean maximum disease severity varied from } 5.1 \text { and } 49.2 \text { on Kohika } \\
\text { and from } 5.5 \text { to } 49.9 \text { on Karamu. }\end{array}$} \\
\hline
\end{tabular}




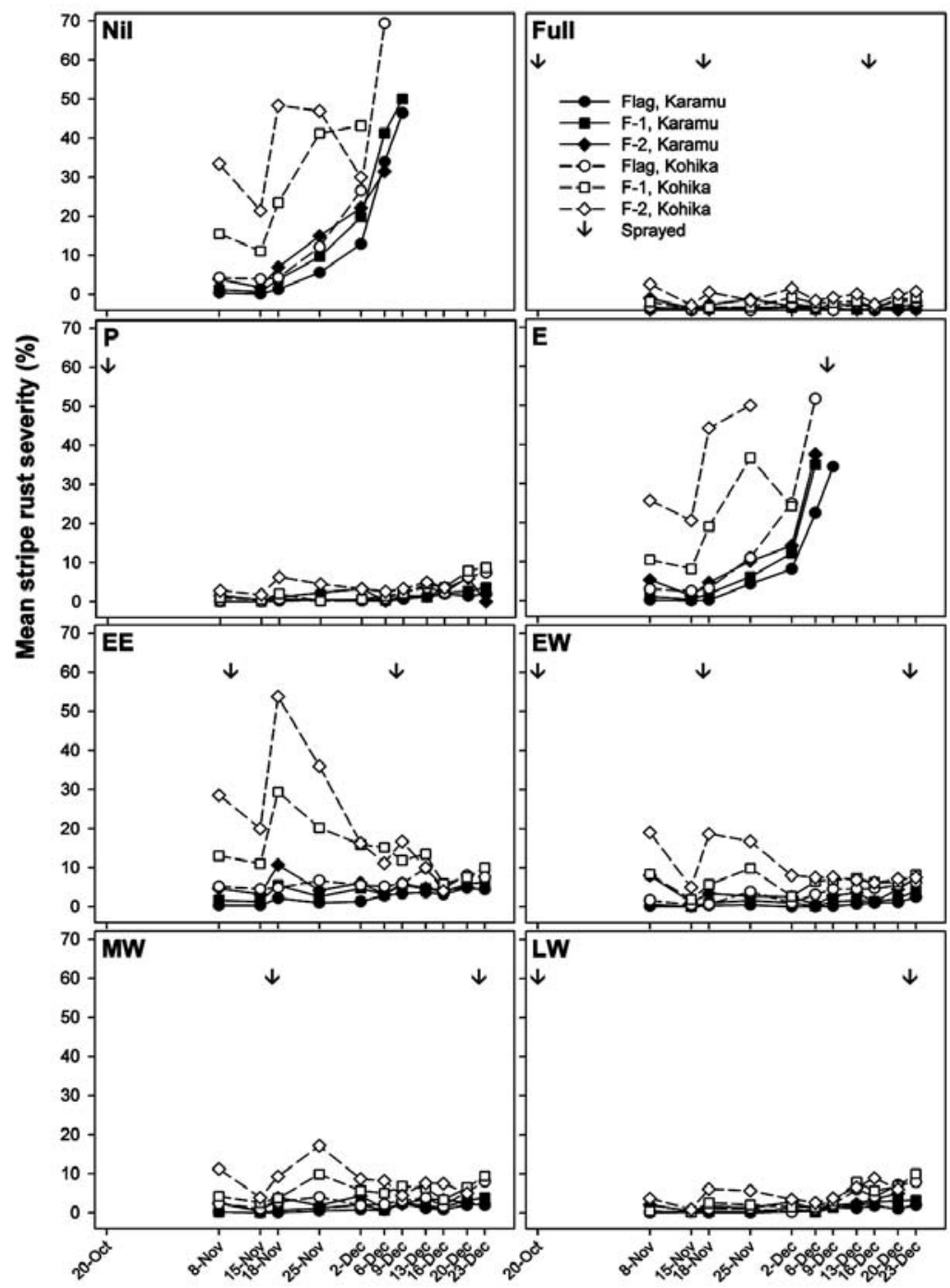

Assessment date

FIGURE 1: Mean stripe rust severity (percentage leaf area infected) for different leaves of two wheat cultivars, Karamu and Kohika, for fungicide treatments Nil, Full, Protectant (P), Eradicant (E), Early eradicant (EE), Early window (EW), Mid window (MW) and Late window (LW) in 2005. Arrows indicate dates when each treatment was sprayed with fungicide. Applications on 16 September for treatments Full, P, MW and $L W$ are not shown. 
For AUDPC, there were significant interactions between cultivar and treatment, cultivar and leaf number, and treatment and leaf number (all $\mathrm{P}<0.001$ ), but the threeway interaction (cultivar, treatment, leaf) was not significant $(\mathrm{P}=0.113)$. The changes in AUDPC with leaf number varied with both treatment and cultivar, with the pattern between the treatments varying between the cultivars. Mean AUDPC was least in the Full, Protectant and Late window treatments for all leaves on both cultivars and greatest in the Nil plots for both cultivars (Table 2). For Karamu, the plots in the Mid window treatment had similar mean AUDPC levels to Full, Protectant and Late window treatments, and AUDPC in the Early window treatment was low on the flag and F-1 leaves. Leaves in the Early window and Mid window plots had lower AUDPC than the Nil plots for Kohika, although AUDPC for these was significantly greater $(\mathrm{P}<0.05)$ than for Full and Protectant treatments. Mean AUDPC generally increased with leaf age for Kohika $(\mathrm{P}<0.05)$, so that flag leaves had the lowest and F-3 the greatest mean AUDPC. The same trend occurred on Karamu leaves, but differences were not significant $(\mathrm{P}>0.05)$.

TABLE 2: Mean area under the disease progress curve (AUDPC) for two cultivars and different leaves of wheat given different fungicide treatments, Nil, Full, Protectant (P), Eradicant (E), Early eradicant (EE), Early window (EW), Mid window (MW) and Late window (LW).

\begin{tabular}{lrrrrrrrr}
\hline Leaf & Nil & Full & P & E & EE & EW & MW & LW \\
\hline Karamu & & & & & & & & \\
Flag & 379 & 16 & 28 & 276 & 103 & 22 & 39 & 27 \\
F-1 & 535 & 31 & 42 & 372 & 197 & 63 & 60 & 54 \\
F-2 & 537 & 103 & 109 & 492 & 301 & 245 & 147 & 115 \\
F-3 & 452 & 174 & 114 & 320 & 414 & 298 & 188 & 208 \\
Kohika & & & & & & & & \\
Flag & 637 & 52 & 64 & 495 & 332 & 146 & 162 & 92 \\
F-1 & 1078 & 99 & 106 & 810 & 863 & 396 & 309 & 136 \\
F-2 & 1501 & 246 & 208 & 1274 & 1465 & 751 & 563 & 250 \\
F-3 & 1473 & 393 & 345 & 1032 & 1612 & 1082 & 699 & 394 \\
\hline
\end{tabular}

LSD $(\mathrm{P}<0.05)$ to compare means in the table:

between leaves for the Nil treatment, one cultivar (within the column, $\mathrm{df} \approx 56$ )

between leaves for any treatments other than Nil, one cultivar (within the column, $\mathrm{df} \approx 56$ )

between Nil Kohika and Nil Karamu, any leaf $(\mathrm{df} \approx 89)$

between Nil treatment, any leaf and any treatment other than Nil, any leaf

(across rows, $\mathrm{df} \approx 89$ )

between any treatment other than Nil, any leaf and any treatment other than Nil, any leaf (between columns, $\mathrm{df} \approx 89$ )

\section{DISCUSSION}

So that growers can achieve best possible control of stripe rust in their crops with maximum returns, it is essential to understand the interaction between timing of fungicide application and fungicide activity and how cultivar resistance, disease risk and pressure and meteorological factors affect these.

The importance of controlling stripe rust early in the growing season was clearly evident in this trial. Two well-timed fungicide applications (Protectant) provided as good control of the disease than three (Late window) or four (Full) fungicide applications. Appropriate timing of fungicide application is crucial to prevent disease spread and development. If fungicide is applied too soon, the protectant activity may have decreased before disease pressure is high. If it is applied too late, the eradicant activity will be insufficient to control the epidemic, as illustrated in the Eradicant and, to some extent, 
Early eradicant treatments. The first fungicide application on 16 September 2005 was very early in the crop development, seedling growth -7 leaves unfolded (GS17), but it may have suppressed any early development and spread of stripe rust by reducing the amount of inoculum available to advance the disease epidemic.

Fungicides are applied to suppress disease development and to protect the green leaf area, which is vital for dry matter accumulation and yield. The top three leaves are most important for grain filling and final yield (Thomas et al. 1989). Farmers aim to protect these leaves from various foliar diseases, including stripe rust, until natural senescence. Studies in the UK have shown that it is vital to ensure wheat is well protected from disease during and after stem extension (Cook et al. 1999). Often fungicides are applied when disease is already present in the crop. Fungicide application in response to the presence of disease in the crop may lead to poor disease control, a perception that fungicides have failed to perform adequately, and to excessive use of fungicides. Yield loss due to absence of fungicide treatment can occur from GS32, but is most consistent from about GS37 (Cook et al. 1999). In some cases two or more applications are required, especially when the cultivar is susceptible to stripe rust, disease pressure is high and environmental conditions are conducive to the development of the pathogen.

Kohika was more severely affected by stripe rust than Karamu. Kohika is susceptible to stripe rust as a seedling and, as an adult plant, it is moderately resistant to moderately susceptible, although it does not contain any of the known genes for resistance to stripe rust (S.L.H. Viljanen-Rollinson, unpubl. data). Karamu contains the gene YrA for resistance to stripe rust, and can be severely affected by the disease if pathotypes containing virulence to this gene are present and when disease pressure is high (ViljanenRollinson et al. 2002). Disease levels in Karamu flag leaves and leaf F-1 reached 50\% in the Nil treatment plots. In this trial, the pathotypes used to inoculate the trial did not contain virulence $\mathrm{YrA}$, but it is evident from the high disease severities on some leaves of Karamu late in the season that inoculum virulent to this gene arrived naturally and caused infection in Karamu. Virulence to $\mathrm{YrA}$ is contained in many of the pathotypes that are common in New Zealand so Karamu would also benefit from a fungicide application when these pathotypes are present and when the environmental conditions are conducive to disease development.

\section{ACKNOWLEDGEMENTS}

Funding was provided by the New Zealand Foundation for Research, Science and Technology. Cathy Munro sowed and managed the trial and Yaolin Deng provided technical assistance.

\section{REFERENCES}

Cook RJ, Hims MJ, Vaughan TB 1999. Effects of fungicide spray timing on winter wheat disease control. Plant Pathology 48: 33-50.

Thomas MR, Cook RJ, King JE 1989. Factors affecting development of Septoria tritici in winter wheat and its effect on yield. Plant Pathology 38(2): 246-257.

Viljanen-Rollinson SLH, Parkes RA, Armour T, Cromey MG 2002. Fungicide control of stripe rust in wheat: protection or eradication? New Zealand Plant Protection 55: $336-340$.

Vyas SC 1984. Systemic fungicides. Tata McGraw-Hill Publishing Co. Ltd, New Delhi, India. $360 \mathrm{pp}$. 